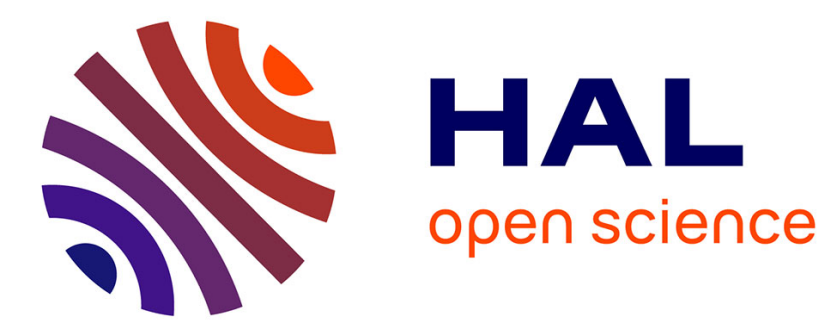

\title{
Cellular Structures under Impact Loading
}

Han Zhao, Ibrahim Elnasri, Hui Jian Li

\section{To cite this version:}

Han Zhao, Ibrahim Elnasri, Hui Jian Li. Cellular Structures under Impact Loading. Materials Science Forum, 2007, 539-543, pp.1880-1885. 10.4028/www.scientific.net/MSF.539-543.1880 . hal-01580893

\section{HAL Id: hal-01580893 \\ https://hal.science/hal-01580893}

Submitted on 3 Sep 2017

HAL is a multi-disciplinary open access archive for the deposit and dissemination of scientific research documents, whether they are published or not. The documents may come from teaching and research institutions in France or abroad, or from public or private research centers
L'archive ouverte pluridisciplinaire HAL, est destinée au dépôt et à la diffusion de documents scientifiques de niveau recherche, publiés ou non, émanant des établissements d'enseignement et de recherche français ou étrangers, des laboratoires publics ou privés. 


\title{
Cellular structures under impact loading
}

\author{
H. Zhao ${ }^{1}$, I. Elnasri ${ }^{1}$, H.J.Li ${ }^{2}$ \\ ${ }^{1}$ Laboratoire de Mécanique et Technologie, ENS-Cachan/CNRS/University Paris 6 \\ 61, Avenue du président Wilson, 94235 Cachan cedex, France \\ ${ }^{2}$ College of Civil Engineering and Mechanics, Yanshan University \\ Qinhuangdao City, Hebei Province, 066004, P.R. China \\ zhao@Imt.ens-cachan.fr
}

Keywords: Foam, Honeycomb, strain rate, Hopkinson bar, Impact. Sandwich, Perforation

\begin{abstract}
This paper presents a study of the strength enhancement under impact loading of metallic cellular materials as well as sandwich panels with cellular core. It begins with a review of likely causes responsible for the strength enhancement of cellular materials. A testing method using $60 \mathrm{~mm}$ diameter Nylon Hopkinson pressure bars is used to investigate the rate sensitivity of various metallic cellular materials. In order to identify the factor responsible for the strength enhancement of those materials, an experimental analysis is performed on a model structure which is a square tube made of rate insensitive materials. Significant enhancement is experimentally observed under impact loading, whereas the crushing mode is nearly the same under both static and impact loading. Finally, an inversed perforation test on sandwich panels with an instrumented pressure bar is also presented. Such a new testing setup provides piercing force time history measurement, generally inaccessible. Testing results show a notable enhancement of piercing forces, even though the skin aluminum plates and the foam cores are nearly rate insensitive.
\end{abstract}

\section{Introduction}

Metallic based cellular materials such as honeycomb, foam, hollow spheres (especially sandwich panels with cellular solid core) are promising structural materials which can be used in lightweight structure, impact energy absorption, acoustical wave attenuation, etc.

A large number of experimental, numerical and analytical studies on the behaviour of cellular materials have been reported in the open literatures [1-6]. However, most of previous works concerns studies under quasi-static loading. There is still a lack of reliable experimental data under impact loading, which makes it difficult to understand the behaviour of cellular solids and their sandwich penal under impact.

This paper presents at first an experimental study on the behaviour of cellular materials under impact loading. Various factors that may be potentially responsible for the strength enhancement of metallic foam are discussed as well as testing methods using large diameter Nylon pressure bars in SHPB set-up and experimental results are presented in Section 2. An analysis on a model-structure (square tubes) in Section 3 shows that the inertia effect is the main reason of measured macroscopic rate sensitivity of studied cellular materials. In the last section, a new inversed perforation impact test on the sandwich panel is presented, which provides an accurate measurement of piercing force time history. A notable enhancement of piercing force under impact is observed.

\section{Nylon SHPB, some experimental results}

There exist some known causes for the rate sensitivity of the cellular materials: namely, the rate sensitivity of the base material, the pressure of the air entrapped in the cell, the shock enhancement, 
wavelength changes, etc. All these potential sources may contribute to the macroscopic rate sensitivity in metallic cellular materials.

Actually, it has been shown in micromechanics analyses that the ratio of cellular material strength over that of the cell wall material depends on a power function of the relative density [1]. From such an analysis, the rate sensitivity of the base material induces the macroscopic rate sensitivity of a cellular material [2]. The strain rate sensitivity of a cellular material may be due also to the existence of a gas/fluid phase $[1,3]$. Taking an open cell foam as an example, when the foam is loaded slowly, the gas filled in the foam can move our without resistance. Under impact, the gas entrapped in cells may have no time to move out. They will then take part in the whole resistance of cellular materials by the pressure increase due to the volume change. The quicker the loading, the more the air is entrapped. At high impact speed $(>50 \mathrm{~m} / \mathrm{s})$, Reid and Peng [7] reported the strength enhancement by the formation of shock wave. If the constitutive relation is concave, a single shock wave front can be formed. However, such kind of concave constitutive function is unusual for solid materials in uniaxial stress condition. For cellular materials, the densification part of stress-strain curve is a concave function and the shock wave may be formed under usual one-dimensional stress conditions. Another possible factor that may cause strength enhancement is the micro-inertia effect. It was shown that the buckling of a column under impact compression occurs at a delayed time because of lateral inertia, so that the apparent critical buckling force is higher than the quasi-static one [8]. It is observed for Balsa wood that the folding wave-length has become smaller [9] under impact loading and this can also explains a higher crushing strength.

Large scale Nylon Hopkinson pressure bars and experimental results Above analyses show that the rate sensitivity of cellular materials comes from various sources. It is therefore difficult to predict the rate sensitivity by a simple theoretical model. Experimental studies are definitely the main investigating means. To perform tests at high strain rates, the most widely used method is the spilt Hopkinson pressure bar test [10,11]. A summary of the development of the SHPB technique can be found [12-13].

However, from an experimental point of view, impact tests on cellular materials using SHPB have two major difficulties. One is the large scatter due to the small ratio between the specimen size and the cell size. To overcome this difficulty, a large diameter pressure bar is necessary to host a larger specimen. Another is the weak signal due to the weak strength of cellular materials, which leads to a low signal-noise ratio. Here, soft nylon pressure bars are used to solve this problems. However, soft Nylon bars are viscoelastic materials and the wave dispersion increases greatly with the diameter of the bars. Kolsky's original SHPB analysis is based on the basic assumptions that the wave propagation in the bars can be described by a one-dimensional wave propagation theory. As the three waves are not measured at bar-specimen interfaces to avoid their superposition, they have to be shifted from the position of the strain gages to the specimen faces, in terms of both time and distance. This shifting needs the knowledge of wave propagations along the bar.

Wave dispersions in a cylindrical bar have been extensively studied in the past decades. Pochhammer and Chree's harmonic wave propagation theory has been used in the data processing. The correction of wave dispersion due to a viscoelastic behaviour coupled with a geometrical effect is necessary for the large diameter Nylon bar. Such a correction is not equivalent to a simple additive correction of a nominal elastic geometrical dispersion and a one-dimensional viscous dispersion and attenuation. As the attenuation coefficient is also affected by the geometric effect, it has been proved [14] that such an approach gives wrong results.

Rate sensitivity of cellular materials - experiments The $60 \mathrm{~mm}$ diameter Nylon Hopkinson pressure bar allows for an accurate measurement, because a reasonable large specimen can be used and the signal/noise ratio is improved by soft Nylon bars. It is applied to measure the rate sensitivity of various cellular materials.

Honeycombs The dynamic out-of-plan behaviours of 5056 and 5052 aluminium honeycombs were studied, which involved three different cell sizes and wall thicknesses. Figure 1a 
shows a typical progressive buckling pattern observed for all the tested honeycombs. Figure $1 \mathrm{~b}$ presents typical mean stress (crushing force divided by cross section) - displacement curves. The bold part is under impact loading, which is followed by the quasi-static test. It shows that the enhancement under impact loading does exist.

Foams IFAM AA6061 foam samples are obtained from Aluminium powder blowing process. The final specimens are cylinders $45 \mathrm{~mm}$ in diameter and $60 \mathrm{~mm}$ long with closed outer skins. The density of the specimen is about $620 \mathrm{~kg} / \mathrm{m} 3$.. It shows an enhancement of about $15 \%$ for the mean flow stress. In contrast, $45 \mathrm{~mm}$ x $45 \mathrm{~mm}$ x $55 \mathrm{~mm}$ Cymat foam samples are cut from foam plates of about $200 \mathrm{~mm}$ thickness manufactured by the gas injection process with an average density is about $250 \mathrm{~kg} / \mathrm{m}^{3}$; There is nearly no notable rate sensitivity. Actually, the failure mode are different. Figure 3 indicates that the main crushing mode is progressive folding of IFAM foam and figure 4 shows the failure mode by multiple cracks of the cell walls of rather brittle cymat foam.

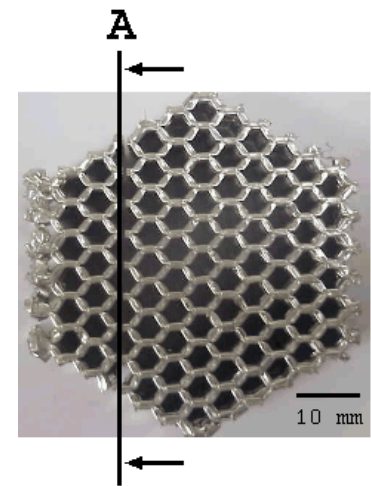

A
$\mathrm{A}-\mathrm{A}$

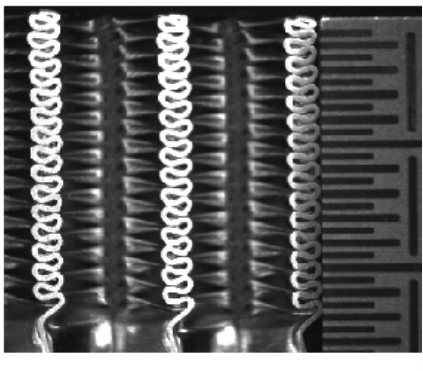

Figure 1. a) Progressive folding pattern; b) A typical mean stress- displacement curve during impact and subsequent quasi-static test

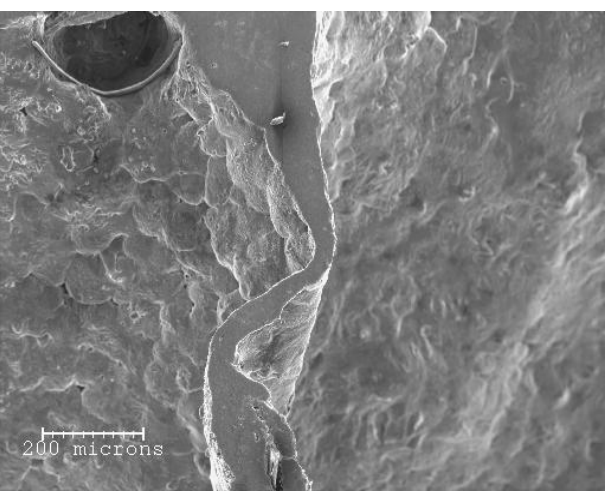

Fig.2 Progressive folding of cell wall of IFAM foam

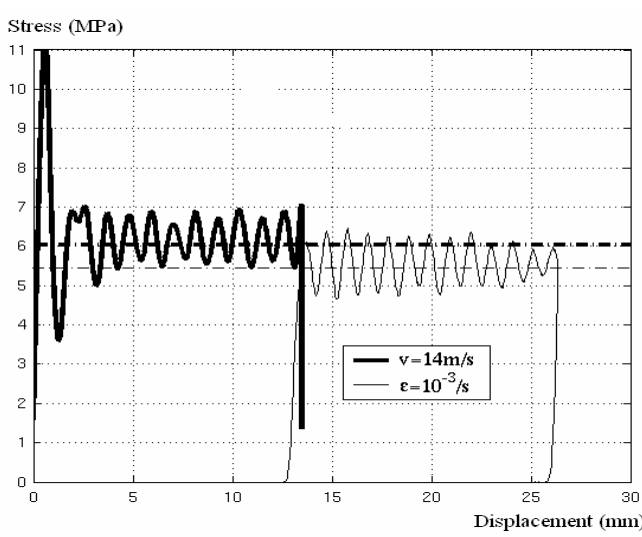

Fig.3 Fractures of Cymat foam

\section{Inertia effect in a successive folding process}

In order to determine the factor responsible for strength enhancement under impact in a successive folding process, we studied a model-structure: commercially available brass square tube (after suitable partial annealing). The observed crushing mode of such tubes is also successive folding of walls. In addition, the behaviour of brass is known to be rate insensitive for a large range of strain rates. Experimental studies of brass square tubes are presented to confirm that strength enhancement under impact can occur without changes in the folding wavelength. Material characterization tests under static and dynamic loading up to $2500 / \mathrm{s}$ were performed to ensure that there is no rate sensitivity for brass in this range of strain rates.

Static crushing tests were performed on heat-treated tubes with a universal testing machine. To avoid a global elastic buckling mode, the length of the tube specimen was chosen as $104 \mathrm{~mm}$. The successive folding mode was observed. The load cell and displacement measurement of the test 
machine were used to record force-displacement signals. The force-displacement recordings were quite repeatable indicating that the heat-treatment applied is reproducible.

For dynamic loading, the direct impact configuration [15] with a large scale SHPB system (diameter $80 \mathrm{~mm}$, input bar of $6 \mathrm{~m}$ and output bar $4 \mathrm{~m}$ ).A typical comparison between static and dynamic tests is shown in figure 6 . We can see that not only the initial peak load but also the successive peak load were measured.

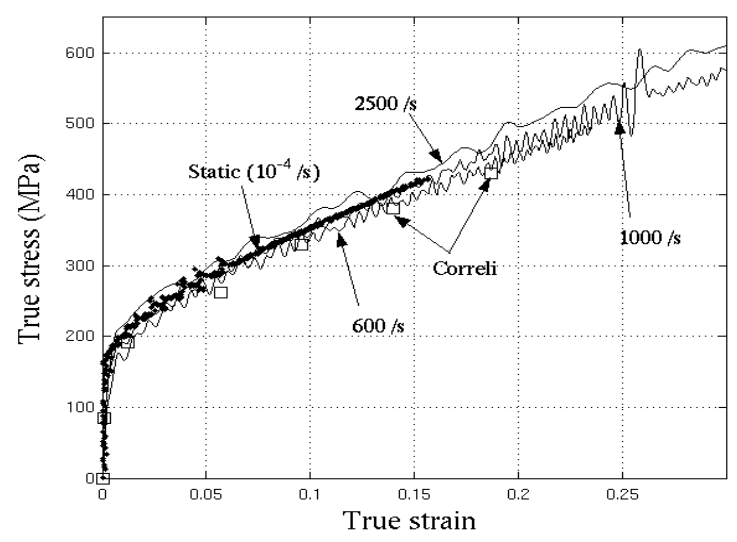

Fig.5 Rate sensitivity of base material

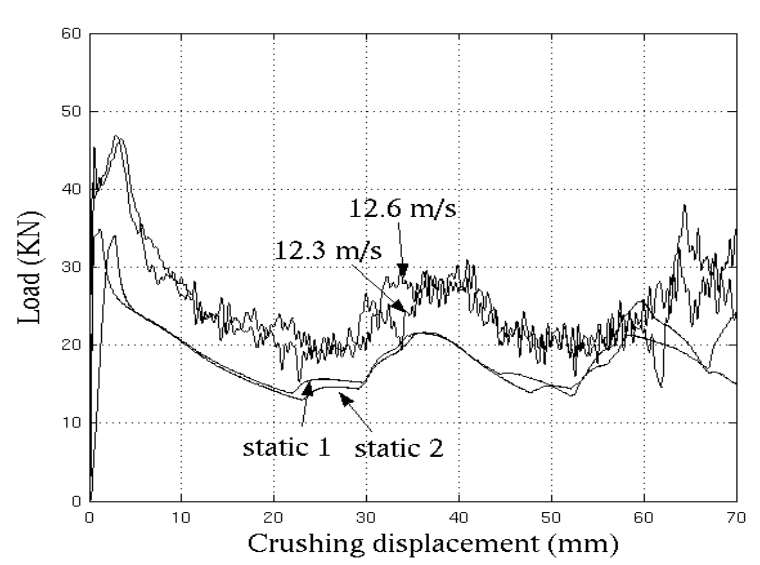

Fig.6 strength enhancement of tubes

It shows that even the base material is rate insensitive, the cellular structure could however exhibit a rate sensitive response [16-17].

\section{Inversed impact perforation test of sandwich penals}

Experimental arrangements The main deficiency of classical penetration/perforation tests is the lack of force record during the perforation process [18-19]. For this purpose, an instrumented long rod can be used at the place of projectile as a Hopkinson pressure bar [10]. However, it was very difficult to launch a long rod at a uniform speed without friction during the test (A length of several meter is necessary because the measuring duration is determined by the length over wave speed in the rod). An alternative is to launch the target sandwich panel to strike the perforating long rod.

Therefore, the proposed inversed perforation testing setup used a gas gun with a $70 \mathrm{~mm}$ inner diameter barrel and a $16 \mathrm{~mm}$ diameter and $6 \mathrm{~m}$-long rod with a semi-spherical nose at one end. The rod is instrumented by strain gauges aimed at accurate force measurement during perforation process. Figure 7 shows an outline of the experimental setup. The target sandwich panel is launched with the aid of a hollow bullet projectile which is made from an aluminium tube with a welded bottom plate at one end. Two Teflon rings are screwed on the tube allows for a small friction between projectile and barrel of the gas gun. The circular sandwich plate is mounted between the open end of the aluminium tube and an aluminium collar. The fixture is realised by six uniformly distributed bolts slightly tightened. Figure 8a gives schematic drawing and figure $8 \mathrm{~b}$ provides an illustration this bullet projectile with a mounted sandwich plate. Such a fixture is close to a clumped condition.

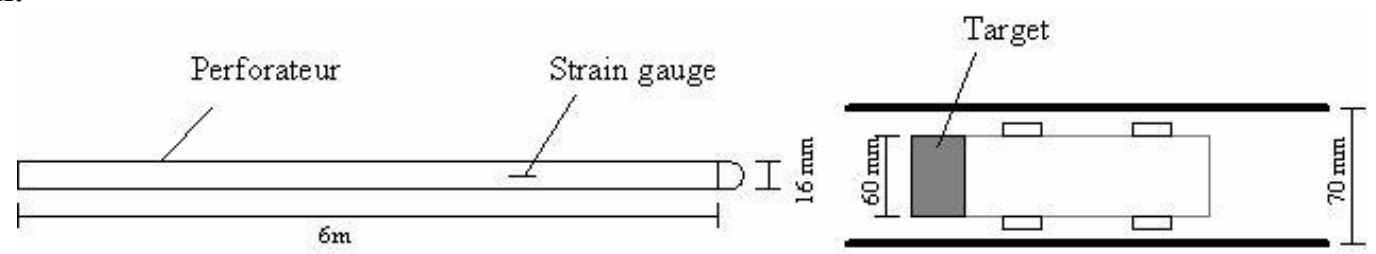

Figure 7 Experimental set-up. 

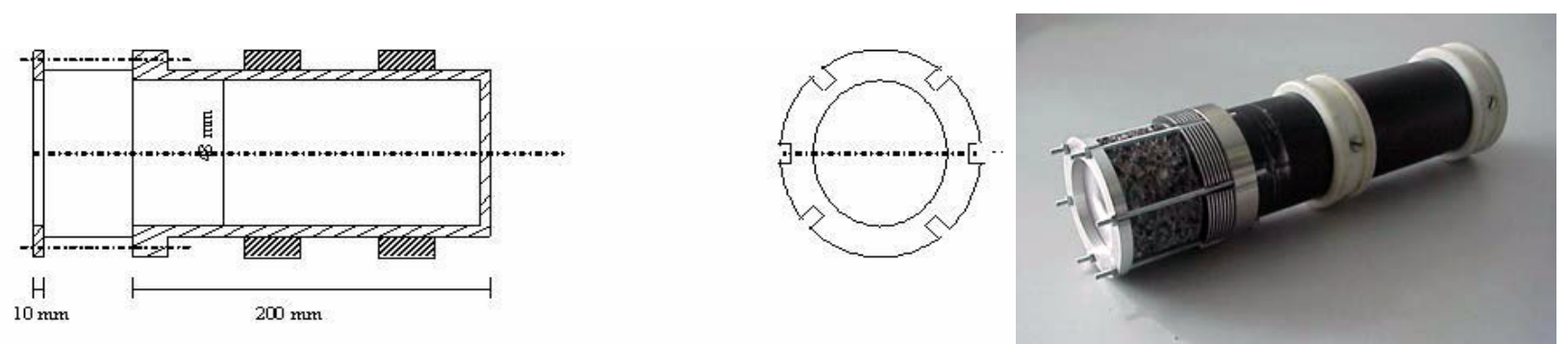

Figure 8 a) details of projectile and clamping ring; b) Projectile

Another technical point is to stop the launched sandwich panel mounted on the hollow bullet -projectile after complete perforation. The adopted solution is use aluminium honeycomb bumper to absorb the residual velocity of the sandwich and projectile. Figure 9 shows the aluminium honeycomb bumper and semi-spherical nose end of the pressure bar.

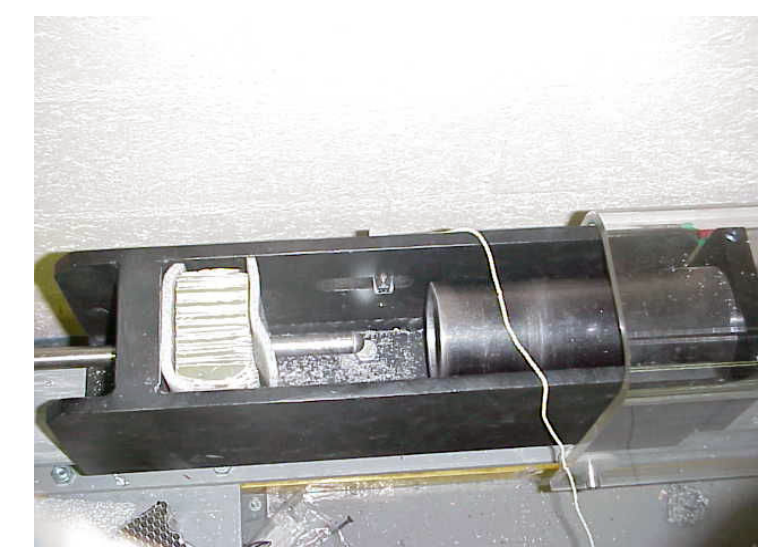

Figure 9 perforation setup;

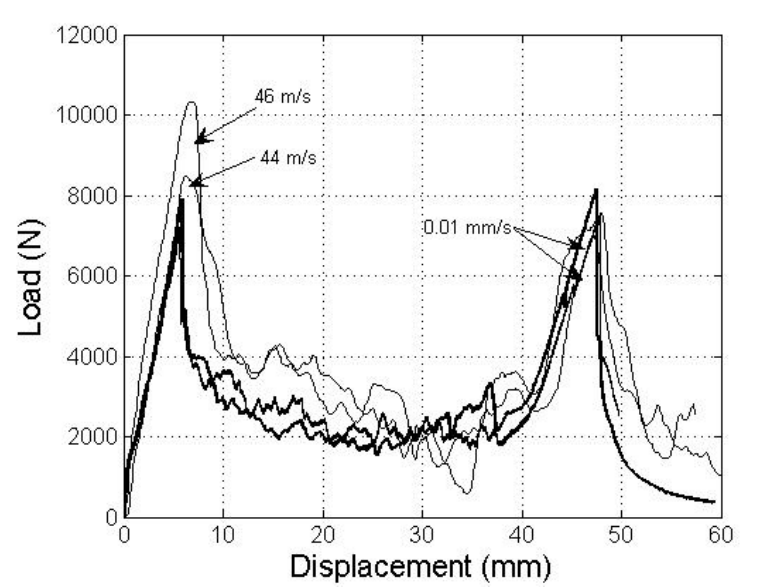

Figure 10 Quasi-static and dynamic curves.

The tube form bullet-projectile together with fixture has a weight of $720 \mathrm{~g}$. The gas gun can launch such a mass to a speed up to $46 \mathrm{~m} / \mathrm{s}$. Perforation tests were performed by firing the mounted target sandwich plate to strike the spherical nosed end of the pressure bar.

Measuring technique with pressure Hopkinson bars. With aforementioned inversed perforation testing setup, the piercing strain impulse can be record by the strain gauges cemented in the pressure bars. The piercing force and velocity time history are calculated by following equation.

$$
\begin{aligned}
& \mathrm{F}(\mathrm{t})=\mathrm{S}_{\mathrm{b}} \cdot \mathrm{E}_{\mathrm{b}} \cdot \varepsilon(\mathrm{t}) \\
& \mathrm{v}(\mathrm{t})=\mathrm{C}_{\mathrm{b}} \varepsilon(\mathrm{t}) \quad \text { Where } S_{b}, E_{b}, C_{b} \text { are respectively the cross sectional area, the elastic }
\end{aligned}
$$
modulus and elastic wave speed of the pressure bar.

The velocity of launched sandwich plate before strike is also available, measured with two optical barriers. With this initial impact velocity, it is possible to estimate the piercing displacement. Indeed, the sandwich plated mounted on the projectile is decelerated by the piercing force measured by pressure bar. In this way, a corresponding force-displacement diagram can be drawn, which make possible a quantitative comparison between static and impact piercing behaviour. These impact piercing results are compared with quasi static tests. A notable enhancement of peak load under impact loading is found (figure 10). Such enhancement is also a structural effect because both the skin plates and the core foam (cymat foam) are rate insensitive.

\section{References}

[1] Gibson, L.J, Ashby, M.F, 1988. Cellular Solids. Pergamon Press. 
[2] Zhao, H., 2004, Cellular materials under impact loading, IFTR-AMAS Edition, Warsaw, Poland. ISSN 1642-0578.

[3] Deshpande, V.S, Fleck, N. A, 2000b. High strain rate compression behaviour of aluminium alloy foams. International Journal of Impact Engineering 24, 277-298.

[4] Klintworth, J.W., Stronge,. W.J, 1988. Elasto-plastic yield limits and deformation laws for transversely crushed honeycombs. International Journal of Mechanical Science 30 (3-4), 273292.

[5] Hanssen, A.G, Hopperstad, O. S., Langseth, M, Ilstad, H., 2002. Validation of constitutive models applicable to aluminium foams, International Journal of Mechanical Sciences 44(2), 359406.

[6] Banhart, J., 2001. Manufacture, characterisation and application of cellular metals and metal foams. Progress in Material Science 46, 559-632.

[7] Reid, S. R., Peng, C., 1997. Dynamic uniaxial crushing of wood. International Journal of Impact Engineering 19 (5-6), 531-570.

[8] Calladine, C.R., English, R. W, 1984. Strain-rate and inertia effects in the collapse of two types of energy-absorbing structure. International Journal of Mechanical Science 26 (11-12), 689-701.

[9] Vural M., Ravichandran G., 2003, Dynamic response and energy dissipation characteristics of balsa wood: experiment and analysis, International Journal of Solids and structures 40, 21472170 .

[10] Hopkinson, B, 1914. A method of measuring the pressure in the deformation of high explosives or by the impact of bullets. Phil. Trans. Roy. Soc., A213, 437-452.

[11] Kolsky, H., 1949. An investigation of the mechanical properties of materials at very high rates of loading. Proceeding of Physical Society B62, 676-700.

[12] Zhao, H., Gary, G., 1996. On the use of SHPB techniques to determine the dynamic behaviour of materials in the range of small strains. International Journal of Solids and structures 33 (23), 3363-3375.

[13] Zhao, H., Gary, G., 1997. A new method for the separation of waves. Application to the SHPB technique for an unlimited measuring duration. Journal of Mechanics and Physics of Solids 45, $1185-1202$.

[14] Zhao, H., Gary, G., 1995. A three dimensional analytical solution of longitudinal wave propagation in an infinite linear viscoelastic cylindrical bar. Application to experimental techniques. Journal of Mechanics and Physics of Solids 43 (8), 1335-1348.

[15] Hauser F. E, 1966. Techniques for measuring stress-strain relations at high strain rates. Experimental Mechanics 6, 395-402.

[16] Zhao, H. and Abdennadher, S., 2004, On the strength enhancement under impact loading of square tubes made from rate insensitive metals, Int. J. Solid Struct., 41(2004) 6677-6697.

[17] Zhao, H Nasri, I. and Abdennadher S., An experimental study on the behaviour under impact loading of metallic cellular materials, Int. J. Mech. Sci.,_47(2005) 757-774.

[18] HooFatt M.S, Park K.S., 2000. Perforation of sandwich plates by projectiles. Composites: Part A: applied science and manufacturing 31, 889-899.

[19] Radin, J. Goldsmith W., 1988. Normal projectile penetration and perforation of layered targets. Int. J. Impact Engng 17, 229-59. 